\title{
A relação entre a substância e a liberdade do homem: uma análise da Ética de Spinoza
}

\author{
The connection between the substance and the human's liberty: a Spinoza \\ Ethics analysis
}

\author{
CLAITON DERLI SEIBERT POERSCH
}

\begin{abstract}
Resumo: O homem sempre travou uma guerra contínua com sua liberdade. Tem medo de se questionar sobre essa realidade, principalmente quando atrelada à Substância (Deus), procurando encontrar recursos para responder se é livre perante esse Ser. Esta problemática da liberdade constitui-se no cerne da presente pesquisa, cujo intuito é apresentar a relação existente entre a Substância spinozana e a liberdade humana. Partindo destas inquietações é que será possível verificar se na relação entre Deus e o homem pode-se afirmar a liberdade deste último para com a Substância, bem como, se é possível afirmar que a Substância é livre. É com a finalidade de responder a estas inquietações, tendo como base Spinoza, que se empreenderá a presente investigação.
\end{abstract}

Palavras-chave: Baruch Spinoza. Liberdade humana. Liberdade da Substância.

Abstract: The human always waged a continuous war with your liberty. Have afraid to question about this reality, especially when attached with the Substance (God), trying to find resources to answer if it is free front of this Substance. This problematic of the liberty it is at the core of this research, whose the intention is present the existing connection between the Spinoza Substance and the human liberty. Starting from these restlessness is that will be possible verify if in the connection between God and man it is possible claim the liberty from this last to the Substance, as well as, if it is possible affirm that the Substance is free. It is for the purpose to answer about these restlessness, based on Spinoza, which will undertaken this investigation.

Keywords: Baruch Spinoza. Human Liberty. Liberty of Substance.

\section{Introdução}

Spinoza, como tantos outros exímios autores da Filosofia, ateve-se à problemática "Deus", que no presente autor recebe a conotação de "Substância". Em sua obra mais insigne acerca dessa temática, Ética, ele quis, partindo de um pequeno grupo de definições e axiomas, posteriormente acrescidos de alguns postulados, explicar com muita audácia a natureza de Deus e da alma humana; concluindo que o soberano bem para o homem, sua salvação, consiste no conhecimento e no amor a Ele, Deus.

É necessário esclarecer que o termo "Substância" se equipararia, em Spinoza, ao termo "Deus". Grosso modo, pode-se afirmar que, para Spinoza, Substância é aquilo que existe, que é eterno e imutável; concepção esta que até coincide com aquela descrita no Êxodo, em cujas linhas descreve Deus como o "Eu sou aquele que

\footnotetext{
${ }^{1}$ Licenciado em Filosofia (PUCPR). Bacharel em Direito (PUCPR) Advogado. Mestrando em Filosofia (UNIOESTE). E-mail: claitonpoersch@hotmail.com
} 
é" (Êxodo 3,14; p. 106), mas que, diferentemente da proposta cristã, cujo Deus escolhe criar, para o filósofo, a Substância age consoante a necessidade e o seu agir não poderia se concretizar de outro modo a não ser aquele perpetrado - "As coisas não podiam ter sido produzidas por Deus de maneira diversa e noutra ordem do que a que têm" (SPINOZA, 1983, p. 109); pois admitir o contrário, permitir-se-ia, inclusive, admitir que a natureza de Deus fosse alterada, o que não é possível, especialmente tendo em vista que à Proposição XVI da Primeira Parte da Ética se apresenta a teoria da causalidade divina, cujas nuances permitem vislumbrar Deus como causa eficiente de todas as coisas.

Para consolidar essa ideia, Will Durant (1996, p. 144) assevera que Deus é "o processo universal e a realidade eterna por trás das coisas [...]”; ou seja, é possível perceber que, para Spinoza, não se pode querer conceber o mundo e as coisas que nele existem sem antes pressupor a existência de um "ser maior" que ao mesmo tempo em que é necessidade, é necessitado, tudo rege, contudo, também Ele, Deus, é determinado, não pode escolher agir ou não. Esse ser maior ao qual se fez alusão, não é outro, senão, a própria Substância, ou Deus.

Embora o filósofo tenha se debruçado sobre tal temática, ele é descrito como um homem ateu por procurar a deidade na Natureza; seu Deus é a substância única, uma substância auto causada com infinitos atributos ${ }^{2}$ e modos infinitos e finitos; ou é descrito como um egoísta psicológico porque afirma que o homem tem como maior virtude o esforço de perseverar em si mesmo podendo sempre agir conforme sua potência; ou é descrito como um homem intoxicado por Deus ${ }^{3}$. Tudo que existe é procedência "divina", ou seja, Deus é causa imanente a tudo (Cf. SPINOZA, 1983, p. 97), pois tudo está Nele e movimenta-se Nele. Assim como todas as coisas existentes, Deus é necessário e, ao mesmo tempo, a atitude de criar d'Ele é algo necessário, pois ele, afirma Châtelet (1995, p.143), é "causa de si e das coisas que necessariamente produz [e] difere radicalmente do criador que escolhe criar". A Substância spinozista não tem escolha na hora de decidir por criar ou não, pois tal atitude é parte integrante da essência divina, da mesma forma que os homens também agem na necessidade, não podem decidir, não há livre-arbítrio e sim servoarbítrio.

Spinoza cria, com isto, uma ontologia, na qual a imanência tem papel fundamental, que é sua própria filosofia e sua Ética onde o conceito unívoco, de ser

\footnotetext{
${ }^{2}$ Espinosa define o aludido conceito como: "Por atributo compreendo aquilo que, de uma substância, o intelecto percebe com constituindo a sua essência." (SPINOZA, 1983, P. 76).

${ }^{3}$ Don Garrett, 2011, p. 19, apresenta a expressão usada por Georg Philipp Friedrich Fheiherr Von Hardenberg, conhecido por Novalis (1772-1801), poeta e filósofo do início do Romantismo Alemão, para contrapor a ideia de ateísmo atribuída a Spinoza e para pontuar - por austeros escritos geométricos - o interesse de Spinoza pelo absoluto (Deus). Don Garret ainda afirma: "Espinosa era um fatalista intransigente e um determinista causal, cujo ideal ético era tornar o 'homem livre'. Ele sustentava que a mente humana e o corpo humano são idênticos; no entanto, insistia que a mente humana pode alcançar um tipo de eternidade que transcende a morte do corpo".
} 
criador e de ser criado, nega a possibilidade de um ordenamento temporal ou hierárquico entre Deus e o que ele expressa (o homem, a pedra, o mundo, o universo inteiro $)^{4}$. O universo inteiro é expressão de Deus em Deus por Deus: a pedra, o homem, o mundo, o universo inteiro, exprimem a natureza de Deus enquanto modos finitos em Deus e por Deus.

Nesse universo inteiro, expressão necessária da natureza de Deus, surge uma questão: o que torna um homem livre? O que torna o homem livre, segundo Spinoza e sua filosofia ontológica do necessário?

Um primeiro esboço resolutório, encontra-se, em Spinoza, no livro Ética, no axioma I, no qual o filósofo esclarece o significado da definição Deus, asseverando ser "tudo que existe, existe em si ou noutra coisa" (SPINOZA, 1983, p.77); e quando o autor afirma que algo existe em outra coisa é o mesmo que afirmar que esse algo não pode existir senão como atributo de um sujeito. Em contrapartida, quando é dito "em si" é que só pode ser sujeito e jamais atributo; "não é uma maneira de ser, mas propriamente um ser" (MOREAU, 1982, p. 30, grifo do autor).

A Substância, então, é concebida como distinta dos atributos, característica esta que é explicitada por Spinoza na definição III de Deus, asseverando que por Substância entende "o que existe em si e por si é concebido, isto é, aquilo cujo conceito não carece do conceito de outra coisa do qual deva ser formado" (SPINOZA, 1983, p. 76). Assim sendo, o Deus spinozano é um Deus Absoluto, incondicionado, que de nada depende para que sua existência se plenifique ${ }^{5}$.

Outro aspecto relevante é o fato de que "Deus não efetua coisa alguma por liberdade da vontade" (SPINOZA, 1983, p. 109). Ora, o conceito de liberdade trazido pelo filósofo pode facilmente ser contraposto ao que se crê comumente, contudo, Spinoza muda o conceito de liberdade como fez com vários outros termos. Liberdade não significa ser livre para fazer o que quiser por uma vontade de qualquer espécie. Livre, para Spinoza, é agir e existir exclusivamente respeitando sua própria natureza sem o constrangimento de outro. E, existir exclusivamente por sua própria natureza sem qualquer constrangimento, significa existir exclusivamente por o que de Deus existe em si mesmo. Expressar o que de divino existe em si, significa se expressar respeitando a sua essência atual (natureza e potência atual conatus) de si mesmo em Deus e respeitando todas as leis de Deus (infinitos modos infinitos mediatos) por seus infinitos atributos (infinitos modos infinitos imediatos) na relação com os infinitos modos finitos. Quanto à vontade, também é preciso

\footnotetext{
${ }^{4}$ HORNÄK (2010, p. 15) assim se expressa: "Iniciando com uma perspectiva ontológica, não devo ignorar que Espinosa trata o seu tema no interior de uma 'ética', e com isso ele examina o significado prático da imanência para o homem até suas últimas consequências. Ele parte de um conceito modificado de causalidade. Adotando um conceito unívoco de ser criador e ser criado, Espinosa nega a possibilidade de uma ordenação hierárquica entre Deus e o mundo.”

${ }^{5}$ Apesar disso, a Substância proposta por Spinoza é, como todos os outros seres, determinada; não age livremente.
} 
analisa-la diferentemente do usual, eis que, para o filósofo o aludido conceito não é, e jamais será, livre, mas sempre necessária; inclusive quando se refere a Deus. E tamanha é a relação entre a Substância e a necessidade que Castagnola e Padovani afirmam que "Deus não somente é racionalmente necessitado na sua vida interior, mas se manifesta necessariamente no mundo, em que, por sua vez, tudo é necessitado, a matéria e o espírito, o intelecto e a vontade" ([s.d], p. 297), ou seja, conceber Deus é tê-lo como um ser que tudo plasma mas que, ao mesmo tempo, é cavalgado, essencialmente, pelas instâncias da necessidade.

\section{A relação entre Deus e a liberdade humana}

\subsection{Deus e a necessidade absoluta}

Conforme já mencionado alhures, a Substância (ou Deus), para Spinoza, é determinada e não escolhe agir, sua ação é simples e pura necessidade e só pode ser considerado livre no sentido de que não é constrangido por outrem. Percebe-se, portanto, que a necessidade da qual a Substância está imbuída não se dá de forma absoluta. O Deus de Spinoza, por ser causa de si e de todas as coisas que nele (Deus) existem, por seus atributos e leis, é a causa do mundo. Se o mundo é efeito necessário de Deus por suas leis divinas, Deus ao se expressar se exprime no mundo. Deus nem cria nem o mundo tem início, visto, de certa forma, o mundo sempre está em Deus. O pássaro, a pedra e Paulo podem deixar de existir enquanto pássaro, pedra e Paulo; mas nunca deixam de existir enquanto essência da natureza de Deus. Há uma só substância em si mesma de absoluta perfeição e, como essência eterna e infinita: a Natureza (SPINOZA, 2012, I, ix). A Natureza é causa de si e de tudo o que nela existe. A Natureza expressa sua absoluta e necessária perfeição e realidade na natureza das coisas.

A única substância, cuja essência e existência é uma verdade eterna e que, portanto, sempre existiu, independentemente do tempo e do espaço, expressa-se em toda sua infinita realidade e perfeição. Essa substância é Deus. Deus se moveu. Deus que em si mesmo restava se expressou. E, se moveu, por suas leis eternas, do único modo que lhe era dado se mover. Ao mover-se, Deus se expressou a si mesmo, por si mesmo, imediatamente, por seus infinitos e perfeitos atributos em si mesmo. Ele se expressou a si mesmo, por si mesmo, em si mesmo. Deus é causa de si (SPINOZA, 1983, p. 93).

E, em seu movimento, Deus é absolutamente livre por agir exclusivamente por suas leis naturais sem ser coagido por ninguém (SPINOZA, 1983, p. 94). Deus é causa livre de tudo, não porque possa fazer o que lhe aprouver, mas porque só Deus existe exclusivamente pela necessidade de sua natureza e só Deus age exclusivamente pela necessidade de sua natureza, logo, só ele é causa livre. 
Deus, ao se mover, o faz se expressando segundo suas divinas leis por seus infinitos e perfeitos atributos em infinitos modos finitos e, entre eles, o pedregulho, o homem, o machado. Quando Deus se expressa, o homem conhece essa manifestação por apenas dois dos atributos de Deus, que são a extensão e o pensamento: o pedregulho (na extensão: o corpo do pedregulho; no pensamento: a ideia do corpo do pedregulho); o homem (na extensão: o corpo do homem; no pensamento: a ideia do corpo do homem) e o machado (na extensão: o corpo do machado; no pensamento: a ideia do corpo do machado). Uma árvore é uma e somente uma e mesma coisa - uma árvore. $\mathrm{O}$ corpo de uma árvore na extensão e a ideia de um corpo de uma árvore no pensamento é uma e somente uma mesma coisa: uma árvore. No pedregulho, no homem, no machado há algo de eterno e divino, não enquanto forma modal, mas enquanto expressão na substância única. $\mathrm{O}$ pedregulho, o homem e o machado podem deixar de existir como pedregulho, homem e machado, como coisas modais finitas, quando, encontrando outro modo finito, com potência maior do que a sua potência, esse encontro resulte em uma relação de não composição, ou seja, de decomposição total que é a morte da coisa em sua forma modal finita. Contudo, mesmo deixando de ser o pedregulho, o homem e o machado que eles são, não deixam de existir enquanto expressão da substância, na substância única pela substância absolutamente infinita onde até então restavam insculpidos, pois "Deus não é somente causa eficiente da existência das coisas, mas também de essência delas" (SPINOZA, 1983, p. 102).

Deus, necessariamente, só pode agir seguindo suas próprias leis eternas e divinas que por serem eternas e divinas não podem de forma alguma ser transgredidas, nem mesmo por Deus. Deus só pode fazer um triângulo seguindo a lei eterna que o define de forma definitiva e determinada como triângulo - isto é ser livre. Agir conforme sua natureza e a natureza de si mesmo nas demais coisas. $\mathrm{O}$ ato livre é o ato necessário em Deus e por Deus.

Ainda, pode-se afirmar que "só Deus é causa livre. Com efeito, só Deus existe pela única necessidade da sua natureza e age somente pela necessidade da sua natureza; pelo que só ele é causa livre (SPINOZA, 1983, p. 94). Embasando-se nisso, é possível asseverar que dentre tudo o que existe só Deus é livre por não ser constrangido por coisa alguma, ou ainda, por ser causa e não efeito, porém, não deixa de ser uma existência necessária. Complementando essa ideia, faz-se mister utilizar-se, ainda, da ideia de Spinoza (1983, p. 109) que afirma que "Deus não opera pela liberdade de sua vontade”, ou seja, quando se faz menção a Deus ou à Substância em Spinoza deve-se ter claro que essa ideia de que ela (a Substância) jamais age na liberdade, mas na pura necessidade, assim como todos os demais seres.

Da mesma maneira que a Deus é inerente o conceito necessidade, as coisas também o são, pois "essa necessidade das coisas é a necessidade mesma da natureza 
eterna de Deus" (SPINOZA, 1983, p. 165), ou seja, quanto à necessidade, Deus e as demais coisas estão no mesmo patamar, pois todos agem na e pela necessidade, assumindo como única diferença o fato de que é de Deus que tudo provêm, também necessariamente. É impossível conceber as coisas sem pressupor, anteriormente, uma causa da qual tudo provém, pois "é de notar que há necessariamente para cada coisa que existe uma causa determinada pela qual ela existe" (SPINOZA, 1983, p. 83), que não pode ser outra, que não a Substância.

Poder-se-ia, certamente, querer rechaçar esse pensamento de que Deus é a causa necessária da qual tudo provém necessariamente, contudo, Durant (1996) apresenta uma ideia que corrobora ainda mais essa reflexão, pois ele assevera que o mundo é um mundo de desígnio, ou seja, nada acontece por haver a possibilidade de escolha, e, sim pelo determinismo que rege o universo. E não só o mundo é permeado pelo determinismo, pois Deus também o é, de tal forma que, conforme Châtelet (1995), a ideia de um Deus agindo de maneira contingente é absurda, pois Deus age, tão somente, na necessidade, constituindo-se, dessa maneira, uma característica indelével da pessoa divina.

Esta condição atinente à Substância denota que a liberdade apregoada pelo filósofo holandês assume um sentido peculiar, eis que apenas Deus é causa livre no sentido de algo que existe só pela necessidade de sua natureza e determina-se a si a obrar.

Tem-se de admitir, portanto, a partir disso, que a Substância não age determinada por fins, pois, se assim o fosse, seria necessário desconsiderar o fator "necessidade" pelo fato que agir com vistas a um fim implica, certamente, vontade, escolha, e essa não é uma característica da divindade spinozana. Além disso, "se Deus agisse para um fim, necessariamente quereria algo de que careceria" (ABBAGNANO, 1992, p. 151), o que é extremamente absurdo, eis que Deus é causa de si, não necessitando de quaisquer outros elementos para ter existência, tendo em vista que o que possui existência em outra coisa é todo o universo, o qual é concebido por Deus e não por si próprio (Cf. SPINOZA, 1983. p. 77).

Acerca deste elemento, o supradito autor, na décima quinta proposição apregoa que "tudo o que existe, existe em Deus, e sem Deus nada pode existir nem ser concebido" (SPINOZA, 1983, p. 89), esclarecendo que todas as coisas existem por causa de Deus e nada no mundo é por si, tal como mostra o primeiro axioma, ou ainda, somente a Substância existe por si e é causa de si ${ }^{6}$.

Não se pode admitir o mundo, contudo, sem conceber, previamente, a existência de um ser supremo - a Substância; que tudo rege, mas que também é

\footnotetext{
${ }^{6}$ A expressão causa de si é usada por Spinoza na primeira definição da parte primeira da Ética, definindo-a nos seguintes termos: "Por causa de si entendo aquilo cuja essência envolve a existência; ou por outras palavras, aquilo cuja natureza não pode ser concebida senão como existente”.
} 
envolvido pela necessidade, pois o próprio Spinoza assevera que "nada pode existir ou ser concebido sem Deus" (SPINOZA, 1983, p. 141). Se Deus, ou a Substância, é cercado pela necessidade, o homem, consequentemente, também o é por ser uma forma de apresentar-se de Deus, ou melhor, o homem também é Deus, e não só ele, mas tudo o que existe.

Quando, anteriormente, citou-se que a Substância não tem vontade, restou evidente que ela é condicionada a agir, ou melhor, ainda, se age é por necessidade ${ }^{7}$. Além disso, "Deus [que é] causa de si e das coisas que necessariamente produz, difere radicalmente do criador que escolhe criar" (CHÂTELET, 1995, p. 143), ideia essa que se apresenta pertinente para ratificar o que foi afirmado anteriormente, que Deus não tem vontade e suas ações são embasadas simplesmente na necessidade.

Enfim, Deus não passa de um "ser" que age na necessidade, porém é dele que tudo provém, está, igualmente, fadado a ser, eternamente, um servo da necessidade, entretanto, como mencionado alhures, Deus também “cria” por necessidade e se assim não ocorresse perderia sua excelsa divindade. Enquanto o mundo segue sua inevitável órbita, Deus, por sua vez, deleita-se na incomensurável necessidade que o engloba, pondo fim aos desejos e vontades.

\subsection{A liberdade humana}

Os homens estão, comumente, envolvidos em paixões e desejos ardentes que os impelem às ações. Admitem serem livres, contudo, esquecem-se de que tudo é afecção de Deus, que tudo dele provém seguindo a necessidade que constitui tudo o que existe. Para corroborar essa ideia, Spinoza (1955, p. 54) afirma que

[...] os homens se supõe livres porque não têm a consciência das suas volições e do seu apetite [...] e não pensam, nem em sonho, nas causas pelas quais são dispostos a desejar e a querer, sendo delas totalmente ignorantes.

Esse é um pensamento que permeia quase todos os homens, pois se acham libertos das amarras da necessidade, mas se esquecem de pensar que se eles desejam é porque há uma força que os impele, que não é, senão, a necessidade. Além disso, o homem só alcança a sabedoria a partir do momento em que se deleita em estar com Deus $^{8}$ : "é cônscio de si mesmo [...], de Deus e das coisas por certa necessidade eterna" (DURANT, 1996, p. 154). Nada pode conferir melhor vida ao homem que a necessidade, o determinismo, pois todo ser é permeado por esse quesito, sendo inevitável tê-lo como companheiro por toda a vida.

\footnotetext{
${ }^{7}$ Afirma-se veementemente essa característica para que se perceba a essência que engloba a Substância: ser necessidade e necessário, concomitantemente.

${ }^{8}$ Esse "estar" presente no texto remete ao fato de que o homem deve ter consciência de que tudo está permeado pela necessidade. O homem só alcançará a sabedoria a partir do momento que consentir com a necessidade.
} 
Em face dessa realidade, pode-se admitir, sem temor, que o homem não é livre, entretanto, ao adentrar nessa temática em Spinoza, percebe-se, primeiramente, que esta característica assume na teoria do filósofo um sentido peculiar, eis que, o conferir liberdade ao homem não significa dotá-lo de liberdade para discernir entre as variadas possibilidades que se lhes apresentam, pois a liberdade reside em outro campo; apenas Deus é causa livre no sentido de algo que existe só pela necessidade de sua natureza e determina-se a si a obrar. O homem, por sua vez, é livre, simplesmente, por ser parte "integrante" da natureza divina, imbuído de força interna para pensar e agir por si consoante certa necessidade inerente não só a ele, mas a tudo.

Se analisada com mais afinco, perceber-se-á que toda história apresenta a ideia de uma pseudoliberdade, apresentando-a como possibilidade de escolher entre, por exemplo, realizar uma determinada ação ou não. Ao dissertar sobre a possibilidade e a liberdade humana em Spinoza, de querer realizar uma ação ou não, deve-se ter presente que não passa de um determinismo, pois o homem está condenado a agir sob as rédeas do que já está designado. E não só o homem, pois Deus, também, está condenado a agir sob o determinismo.

Tudo o que o homem sente, faz, pensa, já foi definido anteriormente. Para corroborar com a presente ideia, faz-se mister apresentar o pensamento de Huisman e Vergez (1982), pois afirmam que o homem não passa de mais um elemento constituinte do cosmos, mais uma peça na máquina do mundo, característica essa presente em várias "filosofias", destacando-se a estoica e a spinozista. Tanto para o estoicismo quanto para o spinozismo a liberdade reduz-se ao consentimento para com a necessidade, dizer "sim", incessantemente, à inevitável sucessão de causas e efeitos. Para não ser radical ao extremo, pode-se afirmar que a liberdade consiste na necessidade de se cometer ações determinadas por sua própria natureza humana, e não por causas exteriores ${ }^{9}$, ou ainda, estar ciente de que, para que se admita a liberdade, crer, concomitantemente, que tudo o que acontece é necessário e concordar com o que é apresentado.

Como é de sapiência, o homem não possui a infinitude como característica, pois "o ser humano, finito, parte de uma totalidade infinita que a todo instante o determina [...]" (CHÂTELET, 1955, p. 124), que não é, senão, o próprio Deus, ou em uma linguagem spinozana, a Substância. Tal ideia se apresenta como sendo de rara importância, pois além de enaltecer a figura da divindade, que tudo plasma e à qual tudo se submete, erige um homem não-livre, marcado com o determinismo que perpassa toda a vida. Percebe-se, então, que o homem está condenado a viver sob as rédeas do determinismo, pois este se constitui como lei que cerceia todo e qualquer ser, inclusive a natureza.

\footnotetext{
${ }^{9}$ Nota-se que, apesar disso, o que está proposto não passa de um determinismo, mas de apresentado de uma forma sutil.
} 
Ainda sobre esse elemento, Spinoza (1955, p. 53), em seu escrito, faz alusão a esse fato afirmando que "tudo foi predeterminado por Deus [...] pela natureza absoluta de Deus", ou seja, por mais que se admita não estar permeado pela necessidade, ela se faz presente e age, às vezes, sorrateiramente. Não é possível conceber, em Spinoza, algo que não seja determinado, pois como foi enaltecido anteriormente, a natureza divina engloba todas as coisas existentes, conferindo-lhes o agir sob a necessidade e, mais do que isso, tornando-as inaptas à liberdade.

Quando Spinoza (1955, p. 33) dissertou acerca desse fato, ele não opôs a liberdade à necessidade, e sim, ao constrangimento, fato esse que é perceptível na afirmação desse mesmo autor ao propor que "Deus age unicamente pelas leis da sua natureza e sem ser coagido por coisa alguma”, ou seja, a partir disso é possível perceber que o próprio Deus, a Substância, só é livre quando o seu agir se explica pelas leis de sua natureza, e somente por elas.

Essas explicações precedentes são de extrema relevância se levada em consideração a contemporaneidade, na qual se costuma colocar em oposição duas realidades - liberdade e necessidade; que, em Spinoza, não se opõem, ao menos em tese. Como comumente há o hábito de opô-las, é plausível apresentar a explicação de Spinoza para não gerar dúbia interpretação quando da leitura do presente.

A liberdade que é proposta por Spinoza não pode ser definida pelo livre arbítrio, mas, e tão somente, pela aceitação do ser humano em estar cônscio que vive e age sob as rédeas da natureza da qual ele próprio faz parte, a necessidade. A partir disso, a liberdade deve ser entendida como aquilo que existe e age, apenas, pela necessidade de sua natureza. Há com Spinoza uma inversão de fatores, pois já não mais se contrapõem liberdade e necessidade, na qual aquela tinha como pressuposto o agir de acordo com o livre decreto e a necessidade focando seu agir em um determinismo fatalista, tudo porque, agora, opõem-se liberdade e coação, ou constrangimento. $\mathrm{O}$ que diferencia não é a ausência ou não da necessidade e, sim, a interioridade ou exterioridade da causa que incita a existir e a agir. A liberdade se constitui como uma necessidade de uma essência de existir e agir de acordo com determinações próprias.

Pode soar como quimera a proposta de Spinoza, contudo, se analisada com mais apreço, o que ele propugna é inovador, pois propiciou voltar os olhares a outra face da liberdade, ou melhor, ele erigiu outra constitutiva da liberdade até então pouco conhecida. Isso não significa que anteriormente não se tenha travado uma discussão, mas em Spinoza ganhou novo fôlego, ampliando ainda mais o vasto campo da Filosofia, em especial o da liberdade.

À guisa de elucidação, frise-se o exposto por Spinoza (1955, p. 14), o qual apregoa que 
[...] livre diz-se a coisa que existe unicamente pela necessidade da sua natureza e é determinada por si só a agir: necessária, ou antes, coagida, a coisa que é determinada por outra a existir e a produzir algum efeito segundo certa e determinada maneira.

Ou seja, se considerado o proposto, é possível inferir que só Deus é livre, pois não é constrangido por ninguém. O homem, por sua vez, só pode ser considerado um ser livre quando guiar suas ações pela razão e reconhecer em si a necessidade (ABBAGNANO, 2000, p. 609). Em outras palavras, o homem só é livre quando imbuído do pensamento do amor a Deus, ou melhor, amando-se ele estará, concomitantemente, amando a Deus, pois ele é uma forma de apresentar-se da Substância, decorrente de certa necessidade.

É perceptível, pois, o fato de que as discussões propostas por Spinoza a seu tempo são em muito consideradas, possuindo um valor inestimável. O verdadeiro homem livre não é aquele que possui o livre arbítrio, mas sim aquele que é cônscio de que age sob as rédeas da necessidade. Sobre isso, Moreau (1971, p. 63) afirma que "quando [o homem] se dá conta da necessidade de todas as coisas, deixa-se de querer o impossível; não se deseja senão o que necessariamente é [...]”, tamanha é a atuação do quesito necessidade na vida de todos os seres.

\section{CONSIDERAÇÕES FINAIS}

Frente aos argumentos e exposições elencadas acerca do pensamento spinozano, é possível afirmar que os conceitos apresentados pelo Filósofo, bem como sua forma de interpretar o problema em questão, são, no mínimo, uma nova forma de interpretar o mundo e os seres que nele vivem.

A partir do exposto nas linhas antecedentes, é plausível destacar a ideia que se constitui o cerne da presente pesquisa: o homem não é livre, e não somente ele, pois Deus, ou a Substância, também está impregnado da necessidade, característica essa que é marca indelével de todos os seres. Pode-se querer fazer uma objeção a essa proposta, querendo afirmar que o homem é livre para poder escolher, dado que é um ser dotado de razão. A essa inquietação Spinoza afirma que a liberdade do homem, se assim quiser chamar a necessidade, consiste em consentir com a necessidade, ou seja, estar ciente de que a vida é cerceada pela necessidade, não havendo possibilidade de existir liberdade no sentido estrito do termo, a não ser aquela acima mencionada.

Não se pode querer fugir à necessidade, pois ela é parte integrante do mundo. Os homens, em muitas instâncias, afirmam serem livres, mas Spinoza, na Ética, apresenta a ideia de que "os homens se supõem livres porque têm a consciência das suas volições e do seu apetite [...] e não pensam, nem em sonho, nas causas pelas quais são dispostos a desejar e a querer, sendo delas totalmente ignorantes [...]" (p. 54, 1955). A partir dessa afirmação é possível perceber tamanha ignorância dos 
homens ao crerem que possuem liberdade, mas só assim pensam, pois desconhecem ou desconsideram a "causa das causas", que é a Substância.

E àqueles que querem rechaçar a possibilidade da existência de um ser, desse Deus, Spinoza afirma que, "se não pode ser dada nenhuma razão ou causa que impeça a existência de Deus ou a suprima, não se poderá absolutamente evitar a conclusão de que ele existe necessariamente" (p. 22, 1955).

Portanto, admitir que o homem esteja disposto à liberdade só é possível se concebê-la como necessidade: o homem parecerá ser livre a partir do momento que consentir com essa necessidade, presente inevitavelmente no mundo, na Substância e também nele. Nada pode fugir à ação da necessidade, e isso explica o motivo pelo qual o homem não é livre, pois está cerceado pela necessidade, que o impele a agir consoante uma única regra: a da necessidade plena.

\section{Referências}

ABBAGNANO, N. História da Filosofia. 4.ed. Lisboa: Presença, 1992.

. Dicionário de Filosofia. 4. ed. São Paulo: Martins Fontes, 2000.

ANDRADE, F. D. Desconstruindo a própria tradição. Discutindo Filosofia, São Paulo, n. 8, p.38-41, 2006.

BENNETT, J. Un Estudio de la Ética de Spinoza. Cidade do México: Fundo de Cultura Econômica, 1990. Trad. José Antonio Robles García.

CASTAGNOLA, L; PADOVANI, U. História da Filosofia. São Paulo: Melhoramentos, [s.d.].

CHÂTELET, F (Org.). História da Filosofia: de Galileu a J. -J. Rousseau. 2. ed. Lisboa: Rolo e Filhos, Artes Gráficas Ltda., 1995.

CHAUÍ, M. Espinosa: uma filosofia da liberdade. São Paulo: Moderna, 1995.

DURANT, Will. A história da Filosofia. 2. ed. São Paulo: Record, 1996.

GARRET, D. (Org.). Spinoza. Trad. Cassiano Terra Rodrigues. Aparecida, SP: Ideias e Letras, 2011.

HORNÄK, S. Espinosa e Vermeer - imanência na filosofia e na pintura. São Paulo: Paulus, 2010.

HUISMAN, D; VERGEZ, A. Compêndio moderno de Filosofia: a ação. 4.ed. Rio de Janeiro: Freitas Bastos, 1982.

JOÃO. In: BÍBLIA sagrada. 4. impressão. São Paulo: Jerusalém, 2002. p. 1842 - 1895.

LEITE, W. W. O Homem livre em Deus por Bento Spinoza. Caxias do Sul. Universidade de Caxias do Sul, 2016, 179 p. [Dissertação Mestrado].

MOREAU, J. Espinosa e o Espinosismo. Lisboa: Edições 70, 1982.

SPINOZA, B. Ética. 3. ed. São Paulo: Atena, 1955.

. Ética. São Paulo: Abril Cultural, 1983. (Coleção Os Pensadores).

. Ética demostrada según el orden geométrico. Trad. Atilano Dominguez. Madrid:

Trotta, 2000. 
Breve Tratado de Deus, do homem e do seu bem-estar. Autêntica. Trad. Emanuel Angelo da Rocha Fragoso e Luís César Guimarães Oliva. Belo Horizonte: Autêntica, 2012. VVAA. “Êxodo”. In: BÍBLIA sagrada. 4. impressão. São Paulo: Jerusalém, 2002. p.103-161.

Submissão: 19. 02. 2019 / Aceite: 20. 08. 2019 